\title{
Diffusion of innovations: Successful adoption needs more effective soft-DSS driven targeting
}

Received (in revised form): 7th April, 2004

\section{Gino Verleye}

has a Masters degree in economic psychology and wrote a $\mathrm{PhD}$ on the performance of missing data solutions for structural equations models. He teaches research methodology and statistics at the University of Ghent in Belgium. His current research deals with customer segmentation and forecasting of new technology adoption and diffusion.

\section{Lieven De Marez}

has a Masters degree in communication research. As a researcher at the Department of Communication Sciences, University of Ghent, he deals with models for technology adoption.

\begin{abstract}
Despite the promising prophecies that usually go hand-in-hand with the introduction of new technologies or any other innovation, they often turn out to be a big disappointment due to a bad introduction and communication strategy. In order to improve these strategies a soft Decision Support System (DSS) was developed by combining a measurement and segmentation tool, the Delphi method-based product specific innovativeness (PSI) scale with the bowling pin marketing communication model. This new combined approach enables a researcher to detect in advance (ie before the actual introduction) the innovators, early adopters, early majority, late majority and laggards for a certain innovation. Based on the resulting segments and profiles, it is possible to develop an introduction and communication strategy that has a better chance of successful customer adoption.
\end{abstract}

\section{INTRODUCTION}

'We can also now focus marketing effort on targeting innovators. Once we have singled them out and understood what drives them, we can write and design our communications specifically to recruit them. We can also choose whatever media are best to reach them with greatest efficiency. In short, in the late 1990s, we have the capability to focus on innovators. But we still have to know who they are. ${ }^{1}$

Communications Sciences, Korte Meer 7-9-11, B 9000 , Ghent, Belgium.

Tel: +32 9264 6885; Fax: +32 9264 6992; e-mail: lieven.demarez@uqent.be early adopters) instead of targeting the entire market at once, when introducing a new product/innovation. In order to improve the odds on a successful introduction he states that it is necessary to 'single out' those most interested in the new product/service (the innovators), learn what drives them (which features of my new product make it interesting for them?) and design communications specifically to recruit and convince them. What he is not saying is how that communication needs to be designed; or how the introduction strategy has to be rolled out. The purpose of this paper is to initiate a way of answering this 
question that was left open by Carter (and many others).

After a short sketch of the situation, the main methods of innovation forecasting ${ }^{2}$ that have been used until today will be mentioned briefly. This will be followed by a description of the authors' measurement and assignment methodology. All this is illustrated with the case of digital television (dTV) in Flanders. ${ }^{3}$

\section{dTV: A FAILING INNOVATION?}

Several reactions from players on markets where dTV has already been introduced, teach us that, again despite the promising prophecies, the acceptance of digital television is not going as smoothly as expected. At the presentation of the German digital zdf-platform, for example, the following remark was made: 'Over much of Europe, digital pay-TV remains characterised by poor take-up ... partly down to badly judged marketing decisions. ${ }^{4}$

Apparently, the adoption of dTV disappoints somewhat in Europe. According to the commentator above, Stuart Thomson (Cable \& Satellite), this is mainly due to badly judged marketing decisions.

At the beginning of 2002 OnDigital changed its name to ITVDigital. The reason for this change of name was the disappointing introduction of OnDigital. ${ }^{5}$ In the Netherlands, the acceptance of $\mathrm{dTV}$ is even more disappointing. Henk de Goede (of the cable company Casema), had to dismiss 25 per cent of his personnel (300 out of 1,200$)$, due to the disappointing take up results of digital television. There were only two solutions, according to de Goede: a 'drastic increase of the price or ... a national innovation fund'. 6

Fritha Sutherland ${ }^{7}$ described the badly judged marketing decisions as 'remote overload: too much too soon'. Companies try too fast to change the customer from a passive television-user to an active and interactive user of a multimedia platform. In the euphoria of what is technologically possible, they suddenly harass the market with lots of applications and possibilities. Would not it be better then to approach the market first with a more basic product, with a 'basic digital package'? A package known not to frighten the larger part of the market.

\section{DIFFUSIONS OF INNOVATIONS: THEORY}

If an attempt is made to link all this to theory, one soon ends up with 'innovation theories'. The basic work par excellence within this tradition is 'Diffusion of innovations' by Everett Rogers (1962). Since 1962, many authors have worked further on this theory, but the core remained the same: when a new product/new technology is introduced, the target market can be divided into five segments along an axis of risk aversion: in the beginning there are the innovators, followed by the early adopters, the early majority, the late majority and the risk-allergic laggards.

The 'innovators' and 'early adopters' can be seen as kind of trendsetters. They have an important 'opinion leader-role' to play towards the rest of the market. One of the most important principles of these innovation theories is the principle of 'copy-behaviour': ${ }^{8}$ early adopters copy the behaviour and product usage of the innovators, early majority copies the early adopters, and in turn is copied by the late majority... The innovators and early adopters are by far the most important segments: not only because they are the first generating cash flow, but also, and even more, because they are the first that have to be copied. 


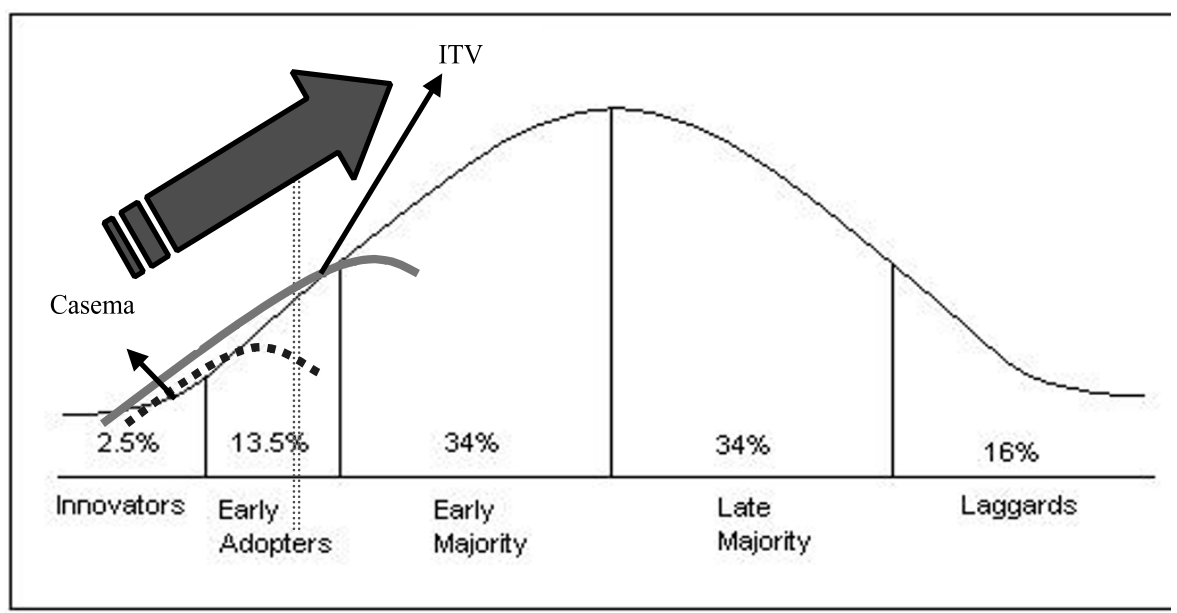

Figure 1: Critical point in adoption or innovation curve

Thinking back to Fritha Sutherland's remark (too much too soon), this could be another reason to start approaching the market with a basic package (instead of the whole product at once). It does not seem very likely that the early majority will start copying the early adopters in their usage of sophisticated applications. For this reason, it seems better to start with a basic product, which the mass market is known to be interested in, and which stands a better chance of starting the copy mechanism. In order to know what this basic product looks like, to know which are the basic applications most of the market is interested in, a research tool is required that will enable the marketer to make a distinction between the five innovation segments for a particular new product in advance.

The critical point in this adoption curve is somewhere around the place (or moment) the early adopters have to start adopting (double vertical dotted line in Figure 1). The diffusion or adoption pattern as presented by Everett Rogers' is used to illustrate this.

Cases like ITV Digital (UK) and Casema (The Netherlands) illustrate that the turning point for the adoption of digital television is coming sooner than expected (cf. Figure 1). It is not that simple to make the step from those first groups (innovators and early adopters) to the mass market. A clear strategy is needed to make the jump towards that mass market. Geoffrey Moore ${ }^{10}$ compares it with a chasm (cf. Figure 1 vertical dotted line) which has to be bridged a chasm that has to be crossed.

\section{HOW TO CROSS THE CHASM? HOW TO REACH THAT MASS MARKET?}

Geoffrey Moore developed his bowling pin model. ${ }^{11}$ In this model for the introduction of innovations he states that in a lot of cases a gradual introduction is better than an introduction by which the whole market is offered the whole product (with all its applications) at once. Instead of haphazardly trying to gain different niches by promoting the product from the start with a whole bunch of applications, he is convinced that it is better, in the initial stage, to concentrate on a few very interested segments. By offering that one or those few segment(s) a product that is tailormade for them (but can also be 


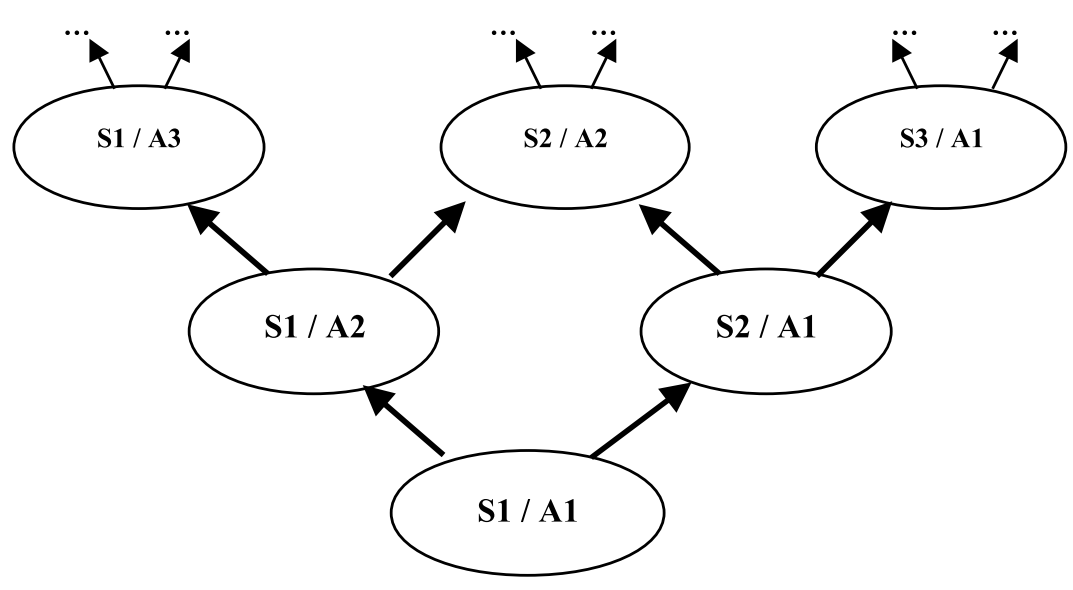

Figure 2: Bowling pin model ${ }^{12}$

situated within the domain of interest of some 'adjacent niches'), the marketer can be practically sure of their adoption. Once they have purchased the product, sales towards those adjacent niches will be easier, because of the already existing word-of-mouth relations between those niche segments, allowing so-called 'references'. What Moore means with this word-of-mouth advertising mechanism is comparable with the idea behind Rogers' copy mechanism.

In Figure 2 the bowling pin model is schematically clarified. Initially the focus is on one segment (S1) which is known to be very interested in the new product, because of one or a few application(s) (A1). The condition for the offered application A1, or the application which is emphasised in communications, is that it has the potential to appeal to other segments after a while. Once the first segment has adopted the application a kind of bowling game starts. A second segment (S2) bearing a close resemblance to the first one, sees how acquaintances/relatives from the first segment are using the new product, the word-of-mouth advertising occurs, and people start to show some kind of copy behaviour (and as a consequence S2 adopts the basic A1). At the same time $\mathrm{S} 1$ is offered a second, new application (A2) - an application that will be adopted by $\mathrm{S} 2$ at the moment S3 adopts the basic A1, and when the first segment $\mathrm{S} 1$ is offered a third application A3, etc. ...

As a consequence, the whole market is reached anyway after some time, offering the total product with all its applications, but in a way that has left more 'adjustment time' for the market to become familiar with the new technology. A bit more time for adjustment can be crucial for a new technology because 'uncertainty' and 'not being familiar' with a new concept appears to be one of the biggest thresholds for acceptance of new technologies. ${ }^{13,14}$

\section{INNOVATION FORECASTING?}

There are three main methods of 'innovation forecasting' that are being used: bibliometrics, econometrics and domain specific innovativeness (DSI) scales. ${ }^{15}$ Each of these traditions is inadequate to give an answer to the questions above.

Bibliometrics is a research tradition in 
which research and forecasts are based on literature research: people search the literature for results and information on/of existing tests, patents, substitutes, introductions in other markets and countries, ... and integrate them into one document, on which conclusions are based concerning the innovations which are to be brought to the market. The authors do not believe that information on previous cases can yield the proper strategy for a new innovative product.

The biggest problem the econometrics tradition confronts is that it does not allow forecasts to be made (before introduction, even when the product is still at the R\&D stage) concerning the adoption curve. The tradition allows very accurate forecasts to be made about the pattern of the curve but it requires at least six to 12 months of data.

DSI scales do allow forecasts to be made, but the authors do not belive they are specific enough. Different authors ${ }^{16,17}$ have developed scales to measure the degree of innovativeness of a person. Innovativeness is seen as a personality trait and is measured by a series of Likert-items. One of the most frequently used DSI-scales is the one developed by Goldsmith and Hofacker. ${ }^{18}$ On the validity and reliability of these DSI-scales, there have been several remarks. ${ }^{19}$

\section{PSI APPROACH}

In order to overcome these deficiencies the authors set out a new approach, the product specific innovativeness (PSI) scale. The scale has to meet certain conditions, it must be:

- simple (the questions must be clear enough to be used in a telephone survey, as well as a personal interview or a street interview);

- applicable when the product still has to be launched, even when the communication strategy has yet to be drawn up;

— from the resulting segmentation, a marketing decision support system must be developed, integrating the segments with communication, product offer and pricing.

The first problem is that the marketer wants to question the consumer about something the consumer does not yet know very well, or even at all. This implies that, before being questioned the consumer has to be informed completely and objectively about the new concept. To do this efficiently, the interviewers need to be well trained: they must all have in mind the same, correct picture of the innovation. Once the respondent is acquainted with the innovation, with the new technology, the interviewer starts with the questionnaire.

The PSI scale consists of three questions, for which there are five possible answers (the same five for each of the three questions). After reading the text, watching the video or testing the innovation, the respondent receives the following question:

'Suppose digital television was already on the market. As you see dTV now, how interested would you be in subscribing to a dTV package?'

This first question is a very general one, asking about a general interest in digital television. There is no specification of price, content offer or applications. The responses are on a 5 -point Likert scale with answers from 1 (I would subscribe immediately) to 5 (I certainly won't subscribe). The answers to this question alone give a general indication of a group of interested people, a group of those not interested and a very big group of those in between. To split up these groups more specifically, the following two questions are needed. 


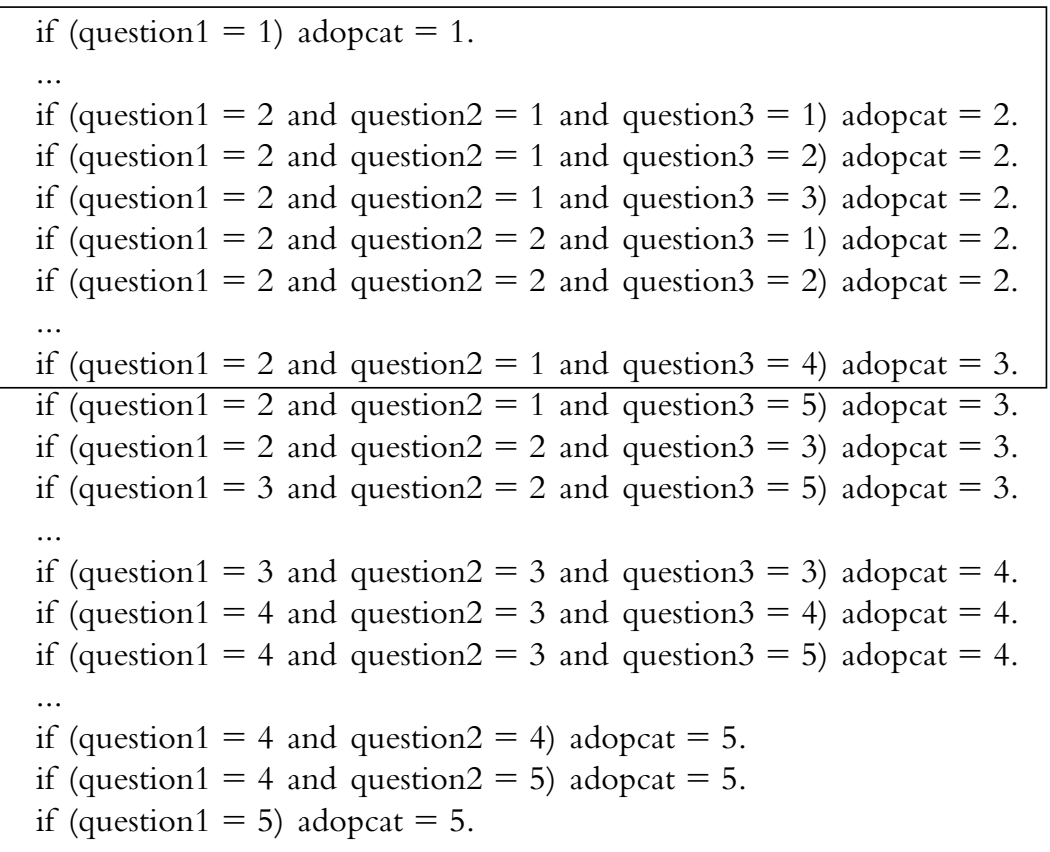

Figure 3: Allocation to the five innovation segments based on the three questions (1: innovators; 2 : early adopters; 3: early majority; 4: late majority; 5: laggards)

'If you were offered an optimal dTV-package ${ }^{20}$ (only the channels you are interested in, the services you want to use, and all that for a price that isn't higher than the price you are willing to pay for it), how interested would you be in subscribing?'

In the foregoing discussion with the interviewer the main interests of the respondent will have become clear (eg someone only interested in an electronic programme guide (epg), e-mail, and more thematic channels (sport and nature)). Knowing this, the interviewer can formulate the third question:

'If you were offered a dTV-package that is not your optimal package, but deviating from it on a certain point (higher price, not all your favourite features ...), to what degree would you be interested in subscribing?'

Using a gradual or stepwise allocation (see Figure 3) on a sample of 621 respondents (see below), a product-specific innovation segmentation is obtained. In order to produce a reliable segmentation category assignment, five experts were recruited and asked to label each combination of answers on the three PSI questions. The five evaluations constitute ordinal indicators and are combined into one final assignment (average inter-expert correlation $=0.76$; Cronbach Alpha $=0.94)$. This methodology is inspired by the Delphi method which has proven added value in the context of adoption forecasting. ${ }^{21-23}$ The dotted line shows the innovation curve as described in theory. The full line shows the curve as forecast in the authors' research, using the PSI scale. Although this line follows more or less the theoretical pattern, fewer laggards and a bigger mass market are found. As for most other innovations or new technologies, there seems to be a small group of people in Flanders willing to adopt digital television immediately. But there is also a large 'waiting and still 


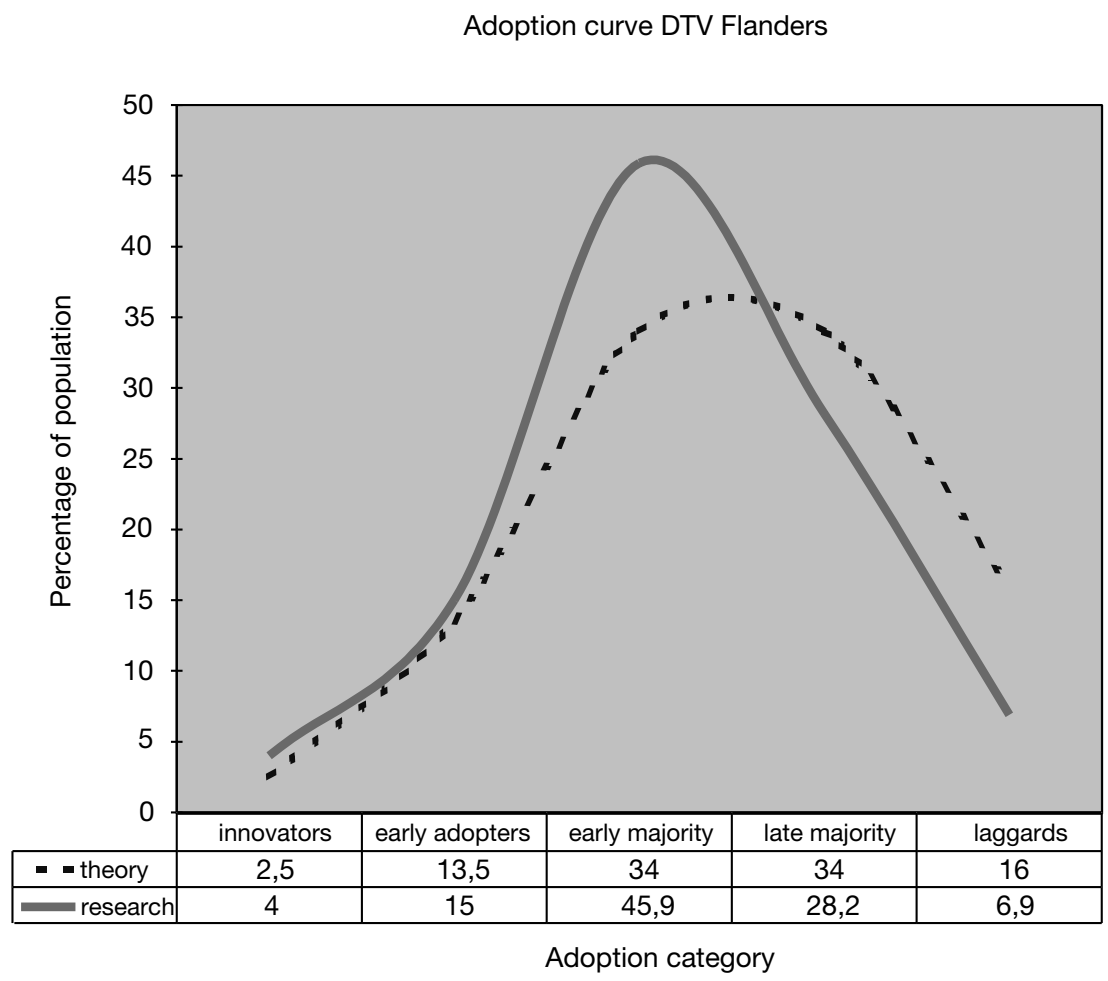

Figure 4: Innovation curve: theory (or results based on DSI) vs. dTV-Flanders (based on PSI)

hesitating' majority: people who only adopt when digital television meets certain conditions (price, applications ...). The next step is to find out what those conditions are, who those people are and how to reach them.

\section{PSYCHOMETRIC QUALITIES}

Next to the high inter-expert homogeneity, the concurrent validity of the PSI scale is assessed by integrating the DSI scale of Goldsmith and Hofacker. $^{24}$

This scale consists of the following six items:

1 In general, I am among the first (last) in my circle of friends to buy a new ......... when it appears.

2 If I heard that a new ......... was available in the store I would (not) be interested enough to buy it.
3 Compared to my friends I own a few of (a lot of ) ..........

4 In general, I am the last (first) in my circle of friends to know the titles/brands of the latest ..........

5 I will not buy a new .......... if I haven't heard/tried it yet. (I will buy a new ......... if I haven't heard/tried it yet.)

6 I (do not) like to buy before other people do.

Based on this scale the following segmentation is obtained (based on the percentiles on the sum scale with the six Likert items): five segments (innovators, early adopters, early majority, late majority and laggards) according to their innovativeness concerning the domain 'ict' (information and communication technologies). It speaks for itself that the result of both segmentations partly correlates. The significant chi-square test 
for Table 1 and the nature of the diagonal reflects this (chi-square $=72.7$; $\mathrm{df}=12, \mathrm{p}=0.000)$. Treating PSI values as an ordinal variable, a LISREL measurement model using all the Likert items behind the DSI scale in one latent variable was fitted to the data. In this model there is a 0.34 correlation between the DSI and the PSI values. The LISREL model has excellent goodness-of-fit: delta $2=0.979$, rho2 $=0.966$. Psychometric Mokken Scalability analysis of the three items, assuming a cumulative order in the three items, yields $\mathrm{H}=0.73$ and scale reliability rho $=0.85$ - indicating a reliable cumulative phenomenon. Predictive validity of the method has been tested in a GPRS study (cellular phones) and was found accurate. ${ }^{25}$

In Table 1 the innovation segments for the domain ict (DSI scale) are in the rows, and the innovation segments for the product digital television (PSI scale) are in the columns. Although these two segmentations correlate to a certain degree, it is clear that these two segmentations are not completely the same. Besides the already mentioned 0.34 correlation, there is also a dense diagonal (figures in bold), illustrating the linear relationship between the two segmentations.

\section{TOWARDS A SOFT MARKETING DSS FOR DIGITAL TELEVISION}

Ever since the Second World War, strategic decisions have been driven and supported by quantitative models, usually known as operations research models or decision support models. Such models are usually purely quantitative in nature although some authors see the emergence of more qualitative approaches that still rely on mathematical or statistical technology. ${ }^{26}$ Such 'softer' DSS are more flexible and more suited to coping with the reality of making business decisions. Softer DSS also copes with 'arithmo-morphism', the belief that there is a unique, mathematically-defined, optimal decision where there is no place for multiple measurements or subjectivity. ${ }^{27}$ This softer decision aid is exactly what this paper is all about: integrating a new measurement technique (PSI) within marketing management decision aids with room for the subjective.

\section{THE SAMPLE}

For this research the authors contacted over 1,000 Flemish households, and asked them if the decision makers for the purchase of (new) communication technologies could be interviewed. 621 of them agreed to this $(\mathrm{N}=621)$. They had to fill out a ten-page questionnaire, including questions on sociodemographic situation, media possession and usage, interactive buying behaviour, lifestyle, DSI scale of Goldsmith and Hofacker (six Likert items), PSI scale, price-setting and interest in dTV applications. Table 2 describes the sample.

Because most people did not know exactly what digital television was, or they had too positive an image of it, the respondents first had to read an introductory text (two pages) on digital television. Afterwards, this text was discussed with the interviewer. This took about ten to 15 minutes. Only when the interviewer was convinced the respondent had a precise and correct image of digital television did they go to the actual questionnaire.

\section{THE FIVE INNOVATION SEGMENTS FOR DIGITAL TELEVISION IN FLANDERS}

Based on the answers to the PSI scale it was possible to split up the Flemish 
Table 1: PSI vs DSI segmentation

\begin{tabular}{|c|c|c|c|c|c|c|c|}
\hline & & \multicolumn{6}{|c|}{ PSI innovation segments (specifically dTV) } \\
\hline & & Innovators & $\begin{array}{l}\text { Early } \\
\text { adopters }\end{array}$ & $\begin{array}{l}\text { Early } \\
\text { majority }\end{array}$ & $\begin{array}{l}\text { Late } \\
\text { majority }\end{array}$ & Laggards & Total \\
\hline \multirow{6}{*}{$\begin{array}{l}\text { DSI innovation } \\
\text { segments (ict) }\end{array}$} & Innovators & 3 & 3 & 9 & 4 & 1 & 20 \\
\hline & Early adopters & 4 & 31 & 45 & 14 & 4 & 98 \\
\hline & Early majority & 11 & 36 & 109 & 55 & 10 & 221 \\
\hline & Late majority & 6 & 21 & 94 & 70 & 14 & 205 \\
\hline & Laggards & 1 & 2 & 28 & 32 & 14 & 77 \\
\hline & Total & 25 & 93 & 285 & 175 & 43 & 621 \\
\hline
\end{tabular}

Table 2: Distribution of education, income and age

\begin{tabular}{lllllll}
\hline Education & LO: & Lsec: & Hsec: & HOKT: & HOLT: & University \\
& $1.4 \%$ & $8.5 \%$ & $31.4 \%$ & $28.8 \%$ & $12.1 \%$ & $17.7 \%$ \\
Income & $<900 €:$ & $900-1250 €$ & $1250-1750 €$ & $1750-2500 €$ & $>2500 €$ & \\
& $13.4 \%$ & $22 \%$ & $28.4 \%$ & $21.8 \%$ & $14.4 \%$ & \\
\multirow{2}{*}{ Age } & $<20$ & 20 & 30 & 40 & 50 & $>60$ \\
& $2.1 \%$ & $28.4 \%$ & $18.4 \%$ & $32.4 \%$ & $15.2 \%$ & $3.5 \%$ \\
\hline
\end{tabular}

Notes: LO: Lager Onderwijs (school for children aged under 12); Lsec: school for children aged 12-16; Hsec: school for children aged 16-18; HOKT: a three-year higher education course; HOLT: a four-year higher education course

sample into five innovation segments according to their interest or degree of innovativeness towards digital television.

In his article 'why settle for the early adopters?', Carter said 'in this way, we can see that 2.5 per cent should be taken as an indicator of the numbers one might find in any particular market, rather than a hard and fast rule'. ${ }^{28}$ According to him, it is wrong to stick to those fixed percentages of 2.5 per cent innovators, 13.5 per cent early adopters .... This theoretical percentage distribution only has to be seen as a global indicator. It is important to remember that there is always a small group that adopts and a segment showing no interest at all. In between there is the big mass market. By using a segmentation, as described above, this is taken into account. So, what Rogers and Schoemaker and Watkins ${ }^{29}$ called 'earlier adopters', ${ }^{30}$ is for digital television in Flanders a segment of 19 per cent of Flemish households (or at least the decision makers for new communication technologies of those households): 4 per cent innovators and 15 per cent early adopters. The 'waiting mass market' consists of 45.9 per cent early majority and 28.2 per cent late majority. The not interested group, the laggards (6.9 per cent) appears to be smaller than predicted by theory.

For the five categories as a whole a positive correlation with age (Pearson $\mathrm{r}=0.125, \mathrm{p}=0.02)$ and the number of children is found $(\mathrm{r}=0.105, \mathrm{p}=0.012)$, and a negative correlation with income $(\mathrm{r}=-0.234, \mathrm{p}=0.000)$. This means that the older someone is, or the more children they have, the bigger the chance of being located somewhere at the rear of the innovation curve. Higher income earners on the other hand are more innovative for digital television. So, those most interested in digital television are young people, without children and with an income that is higher than average. Apart from this, these five segments differ, of course, on a lot of other 
variables. It can be summarised as follows: the innovators for digital television in Flanders are young (mid-30s), well-educated people, not having much leisure time (a lot of self-employed people and executives). They describe themselves as active PC-users, and 'heavy readers' of newspapers and magazines. In their leisure time they like to go out, and show who they are by their choice of music, clothing and the following of trends.

Within this category there is also a remarkable share of students, singles and lower incomes $(<900 €)$. The latter is not that surprising if account is taken of the phenomenon of 'credit-buyers'. This share of lower incomes within the innovators was also seen for such things as wide-screen television, WAP and games computers. They may be buying on credit, but by being among the first to have these technologies they create a sort of identity.

The monthly amount these innovators are willing to pay for dTV is, on average, about $30 €$. This is an average for the whole segment of innovators. If students (no income) are not included this 'willing to pay'-average increases to $40 €$ a month. If only the self-employed are considered an average of $50 €$ a month is reached.

Besides this, the segment of innovators deviate slightly from the 60/40 male/female distribution. Within these innovators there are proportionally more men (70/30). Concerning media usage innovators can be considered as a segment of 'heavy surfers' and 'heavy viewers' - they surf on average 50 minutes a day and watch television for two hours a day.

Although the Flemish early adopters have a similar profile to the innovators, the price they are willing to pay is significantly less: about $22.5 €$ a month.
This group, however, is somewhat older (38 years), more environment conscious and social minded compared to the other segments. ('Social minded' means spending more time with family and friends.) This segment, with the biggest share of non-married couples living together, surfs the most (over one hour a day) and is medium viewer (1.75 hours a day). Surfing is something they do for leisure as well as for professional purposes.

The early majority have an average age of 40 years and are willing to pay about $20 €$ a month for digital television. It is a segment with significantly more lower/mid-level employees, reading a lot of newspapers and using PCs mainly for professional purposes. Socially, they have a 'lower profile' (less social activities and spending less time with friends and family) than the other segments. They are medium surfers (about 45 minutes a day), but they do this mainly for work, not in their leisure time. They watch about 1.75 hours television a day.

The late majority want to pay $15 €$ for digital television and have, except for the bigger share of lower incomes $(<900 €$ and 900-1250€), a similar sociodemographic profile to the early majority (average age also around 40). This late majority segment especially distinguishes itself by its media usage: it reads fewer newspapers and magazines, but watches a lot of television (over two hours a day). They are less experienced with the internet (30 to 40 minutes a day).

For the laggards the monthly price for dTV cannot be more than 7.5-9.5€ a month. It is an older ( $>45$ years), low-educated segment with a low income. As the late majority, they also show a low media usage (for newspapers as well as magazines, internet and television). Although almost everyone has a computer at home, it is rarely used by 


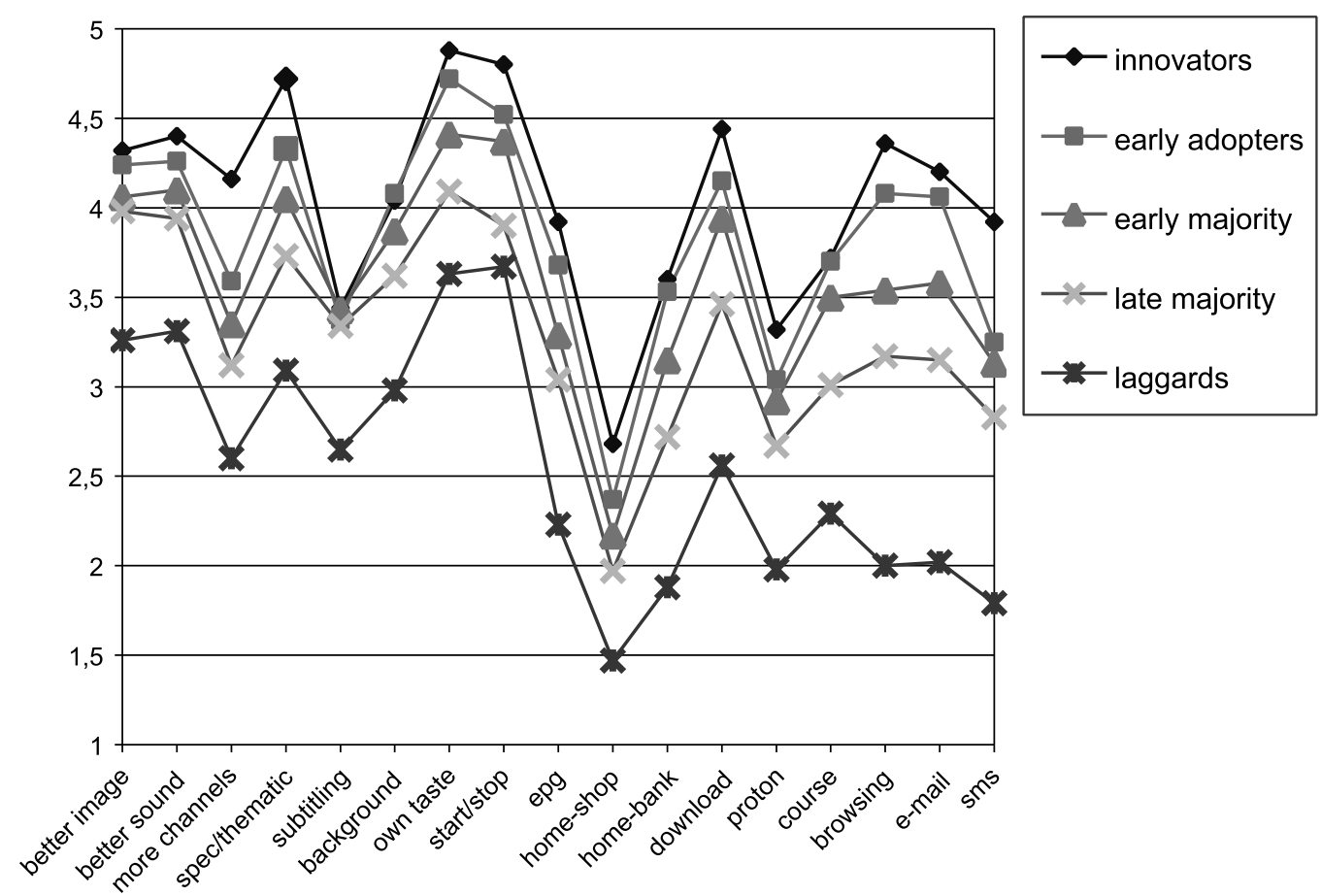

Figure 5: Interest in dTV applications (segments based on PSI scale); $5=$ very interesting

these respondents (decision makers for new communication technologies). These computers are probably used by the children.

\section{INTEREST IN APPLICATIONS}

In order not to restrict the adoption to that small segment of innovators, and to get digital television adopted by the biggest possible share of the market, it is crucial to have a thorough insight in the interest these innovation segments have in several dTV applications. Also, in the search for so-called 'killer applications', it would be useful to know which applications the global market is more or less interested in, and in which the interest is more segment concentrated. The $17 \mathrm{dTV}$ applications that were tested in this study were:

— better image quality;

— better sound quality;
- more channels;

- more specific/thematic channels;

— subtitling in different languages;

- additional background information;

- choosing films/programmes according to taste/choice;

- ability to start/stop/pause a programme;

- epg;

- home shopping;

- home banking;

— downloads for delayed watch;

- proton (loading pay card for small expenses);

— interactive courses;

- browsing the net on the television;

— send and receive e-mail;

- sms function.

Looking at Figure 5, it is clear there are significant differences between the different segments. The five 'interest lines' of the innovation segments run more or less parallel, and in a logical 


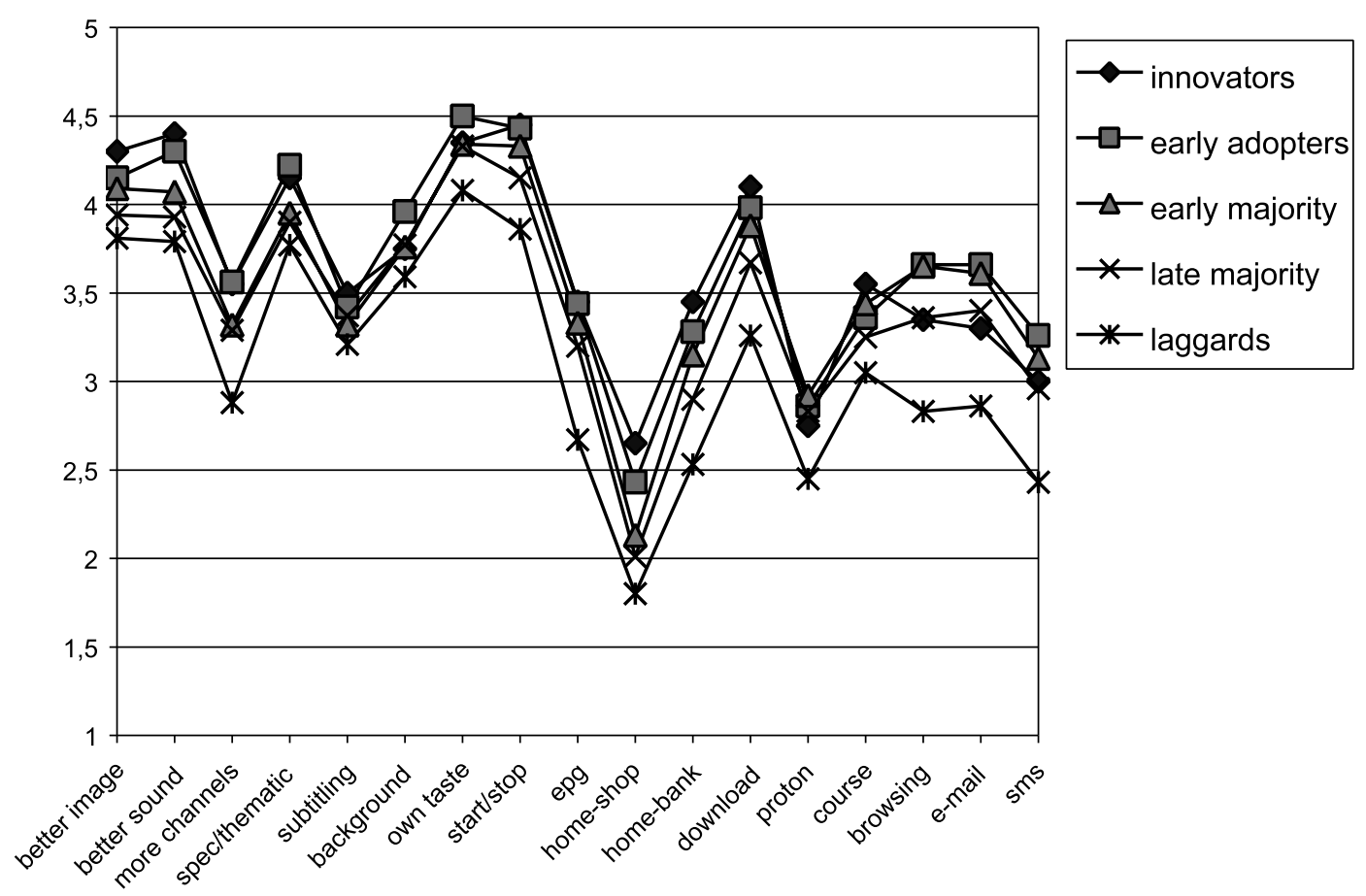

Figure 6: Interest in dTV applications (segments based on DSI scale); $5=$ very interesting

sequence. ('Logical' meaning that interest in the applications decreases towards the end of the adoption curve. Innovators are for almost all applications the most interested; early adopters are generally less, but still quite, interested, and laggards are the least interested.

Kruskal-Wallis and Anova tests yield significant differences between the five segments. Except for subtitling (significant at the 0.05 level), all differences are significant at the 0.01 level.

Further statistical analysis shows that the PSI approach is much more sensitive than the DSI approach. ${ }^{31}$ A comparison of Figures 5 and 6 reveals this.

\section{BOWLING PIN DSS MODEL FOR DIGITAL TELEVISION IN FLANDERS}

The best way to implement all this information in order to obtain the most efficient marketing strategy is still open to debate. In the authors' opinion, Geoffrey Moore's 'bowling pin model' reasoning is the best way to do this. This means that a plan of communications could be as presented in Figure 7.

For example, a basic package could be offered for a price of $7.5 €$ up to $10 €$ a month. This package could contain applications such as epg, the possibility of starting and stopping programmes and asking for additional background information with news, journal and current affairs programmes. Besides the content focus on news and current affairs, the documentary genre could also be included in the basic package. These are the things that appeal to almost the entire market ${ }^{32}$ and deserve emphasis in the initial mass media campaign. Also, the emphasis on 'more channels' cannot be excluded from this campaign. This initial mass media campaign is illustrated by the long dotted line at the right 


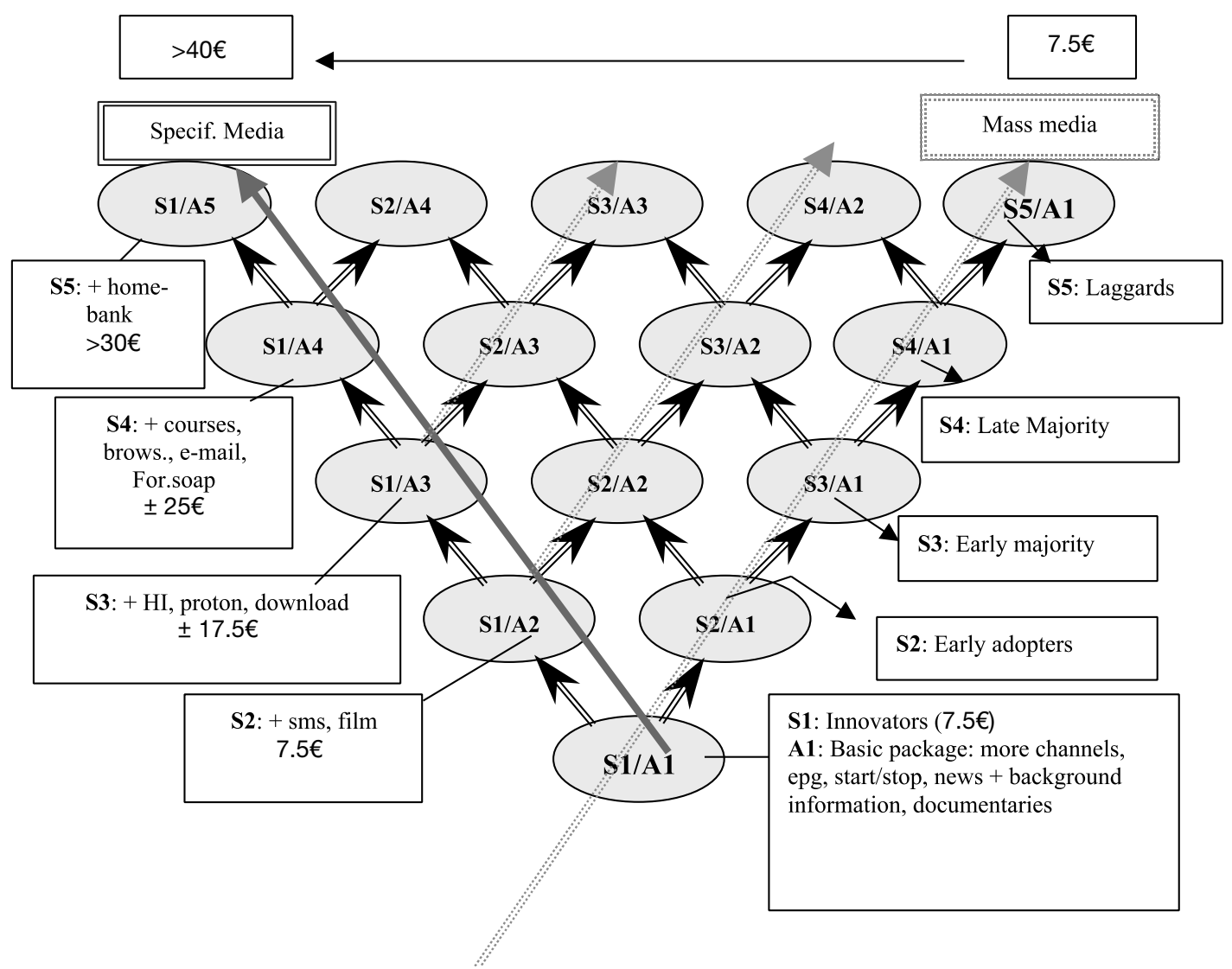

Figure 7: BPM DSS for digital television in Flanders

pointing to the right upper corner, and going from S1 to S5. By choosing this basic package at this stage not much wrong can be done. Practically the whole market is more or less interested in it, and the price is not higher than the price the least interested segment (laggards) is willing to pay for it. Also, to get everybody acquainted with this unknown product, the mass media are the best channel to choose in this initial stage.

By starting with an offer of such a basic package (which the greater part of the market is interested in and willing to pay for), the market is also given some time to grow familiar with the digital television concept: time to get used to the fact that the 'traditional event of watching TV' will be accompanied from now on with a certain degree of interactivity and a certain degree of controlling what is on the screen. A lot of people would immediately give up if they were to be offered 'the total package' at once (at the full price, too expensive for a lot of people, and with all of its applications, a lot of them not interesting enough for a lot of people), but they now have the time to learn to appreciate the concept. By having this time, there is also more time for the marketers to prepare and to prepare the market for more interactivity and more sophisticated applications. Applications such as sms, sending and receiving e-mails, VOD will be better offered later for this reason. Once sales of the basic 
package begin to roll - or once the pins on the right side of the bowling game begin to fall (copy behaviour ${ }^{33}$ ) more sophisticated applications (A2, A3, A4 ...) can be offered.

By using targeted communication (full line pointed towards the left upper corner) towards these innovators and early adopters (their specific media usage is known and they can be reached by dTV because they have already adopted it for the basic package A1), these segments can be prepared for additional dTV applications (with higher monthly fees). In the first expansion of the product, people can be offered an sms application and a film-channel/VOD application (Application 2). In the next stage Application 3 can be offered: the reloading possibility for pay card and download applications, etc. For Application 2 and at the price for $\mathrm{A} 1+\mathrm{A} 2$ (about $17.5 €$ a month) there is still big potential in the market: it is assumed that only the laggards (16.9 per cent) will no longer be interested which still leaves 93.1 per cent of the market as potential customers for A2. For Application 3, there will still be broad interest (and willingness to pay): innovators + early adopters and early majority (together 64.9 per cent of the market). Once the innovators and early adopters have become aware of, and familiar with, the new additional applications through specific targeted communication towards them, there is a good chance these very innovative segments will adopt the product. Once they have adopted it, the emphasis in the mass media campaign (dotted lines pointed to the upper right corner) can change. Once the innovators (S1) have adopted the second application A2, they will be copied by the rest of the market. It is known that the potential for copying the use of this application is big (93.1 per cent), thus there is little risk in changing the emphasis of the mass media campaign (instead of promoting only the basic package, the emphasis also touches on sms and VOD). The same goes for A3, also an application still appealing to a large part of the market (64.9 per cent): once the specific segment-targeted communication has done its work and the innovators have adopted this application, this application can also be included in the mass media campaign. By offering these applications a bit later (not immediately on introduction), and by working initially with targeted communication towards S1 (and S2), and only then communicating and promoting through mass media channels towards the whole market, the necessary copying behaviour is given more time to develop. This also reduces the odds on overwhelming and frightening the 'initially less interested segments'. It even accounts for the fact that some habituation to a new concept is needed, if people are to take up the product.

Therefore, the basic package is promoted first through the mass media, and additional (and more sophisticated) applications are promoted later. Each additional offer will imply a gradual increase of the subscription rate. This additional offer will initially be promoted by targeted (segment-tailored) communication, and only afterwards through mass media campaigns. This communication strategy of 'first targeted, delayed mass media' is only useful in promoting additional applications that have a relatively big potential. This 'first targeted, second mass media' strategy is illustrated in Figure 7 by the area between the three dotted arrows pointing to the upper right corner. To the right of this area communications can be done through the mass media. To the left of this area mass media will no longer be useful because the interest is no longer that big. S4 and S5 only appeal to the 
innovators and early adopters: a market share that is too small to approach through the mass media. So, to the left of this area only specific media (specifically targeted) are used. Within this area a combination of specific and mass media is used. So, as soon as the interest in the additional applications is limited to the innovators and early adopters (for A4 and A5 this is the case), only a specifically targeted strategy of communications is used. A4 and A5 are also the applications that will need the most persuasive power to yield successful adoption. Vague mass media messages will no longer be sufficient here, which makes a strategy of specifically segment-tailored communication, ${ }^{34}$ the best. A strategy in which the marketer can go deeper into things and through which the applications and their use can be situated in line with the lifestyle of those segments.

In this way, the whole market can be reached as much as with the total product (with all its applications) — with the difference that not all applications were offered from the start to everybody, only to those who were interested and willing to pay for them. This results in different packages and different forms of subscriptions to digital television in a price range of $7.5 €$ up to more than $40 €$ a month.

\section{CONCLUSION AND FUTURE RESEARCH}

The combination of the new Delphi method-based PSI scale with the bowling pin model within the framework of a soft decision system allows for a better marketing and communication strategy before the launch of new technology. This methodology has been applied in several commercial studies (eg universal mobile telecommunications system (UMTS) and broadband) where the added value was recognised by marketing communication professionals. The next stage of development includes multiple suboptimal propositions and the development of a statistical model that computes and describes the innovation adoption segmentation where innovativeness is modelled as a latent variable with declining intensity.

\section{References}

1 Carter, J. (1998) 'Why settle for "early adopters"?', Admap, Vol. 33, No. 3, pp. 41-44.

2 Here 'innovation forecasting' means the prediction (in advance) of innovation categories for a specific new product, the detection of those segments and the making of a profile of those segments, before the product is launched.

3 At the time of writing (February 2004) digital television still has to be introduced in Belgium. Within the near future, several players have plans to do so, which makes dTV an ideal test case.

4 Thomson, S. (2001a) 'Free interaction', Cable E Satellite Europe, June, p. 2.

5 Thomson, S. (2001b) 'Lifting the gloom', Cable E' Satellite Europe, July/August, p. 2.

6 Giesen, P. (2004) 'De val van digitale televisie', De Morgen, 7th February, p. 22.

7 Sutherland, F. (1999) 'Remote overload: Too much too soon?', Cable \& Satellite Europe, July, pp. 46-49.

8 Carter (1998) op. cit.

9 Rogers, E. M. (1995) 'Diffusion of innovations', 4th edn, The Free Press, New York, p. 262.

10 Moore, G. A. (1999) 'Inside the tornado', HarperCollins, New York, p. 13.

11 Moore, G. A. (1994) 'Crossing the chasm', HarperCollins, New York.

12 Ibid.

13 Flaherty, N. (2001) 'TV gets personal', Cable $\mathcal{E}$ Satellite Europe, June, pp. 10-16.

14 Professor Parasuraman's 'Technology Readiness Group' (2001) also emphasises the importance of the 'comfort level' factor when it comes to the acceptation of innovations. They describe it as 'a feeling of control (or lack thereof) over technology'. It is a kind of 'uncertainty factor' covering consumer feelings as 'the technology is too complex', 'a lack of trust in tech support', 'getting overwhelmed by the technology'.

15 Watts, R. J. and Porter, A. L. (1997) 'Innovation forecasting', Technological Forecasting and Social Change, Vol. 56, pp. 25-47.

16 Leavitt, C. and Walton, J. R. (1988) 'Openness of information processing as a moderator of message effects on behavior', faculty working paper, College of Business Administration, Ohio State University.

17 Price, L. L. and Ridgeway, N. M. (1983) 'Development of a scale to measure use 
innovativeness', Advances in Consumer Research, Vol. 10, pp. 679-684.

18 Bearden, W. O., Netemeyer, R. G. and Mobley, M. F. (1993) 'Handbook of marketing scales. Multi-item measures for marketing and consumer behaviour research', Sage Publications, New York, p. 59.

19 Flynn, L. R. and Goldsmith, R. E. (1993) 'A validation of the Goldsmith and Hofacker innovativeness scale', Educational \& Psychological Measurement, Vol. 53, No. 4.

20 An optimal dTV package is discussed with the interviewer, for example, what price, which applications.

21 Wright, D. (1998) 'Analysis of the market for access to broadband telecommunications in the year 2000', Computer Operations and Research, Vol. 25, No. 2, pp. 127-138.

22 Ward, P. and Davis, B. J. (1999) 'The diffusion of interactive technology at the customer interface', International Journal of Technology Management, Vol. 17, Nos. 1 and 2.

23 McBurney, P., Parsons, S. and Green, J. (2002) 'Forecasting market demand for new telecommunications services: An introduction', Telematics and Informatics, Vol. 19, pp. 225-249.

24 Goldsmith, R. E. and Hofacker, C. (1991) 'Measuring consumer innovativeness', Journal of the Academy of Marketing Science, Vol. 19, Summer, pp. 209-221.

25 De Marez, L. and Verleye, G. (2004) 'ICT innovations today: making traditional diffusion patterns obsolete, and preliminary insight of increased importance', Telematics \& Informatics, forthcoming.
26 Rivett, P. (1994) 'The craft of decision modelling', John Wiley \& Sons, New York.

27 Roy, B. (1999) 'Decision aiding today: What should we expect', in Gal, T., Stewart, T. J. and Hanne, T. (eds) 'Multiple criteria decision making, advances in MCDM models, algorithms, theory and applications', Kluwer's International Series, Boston. 28 Carter (1998) op. cit.

29 Watkins, T. (1985) 'The economics of the brand', McGraw-Hill, London.

30 With 'earlier adopters' they meant the collection of innovators and early adopters. Because the segment of innovators is often too small for effective targeting and marketing, they thought it was better in some cases to consider those two segments as one group.

31 De Marez, L. and Verleye, G. (2002) 'Diffusion of innovations', extended working paper, University of Ghent, Dept. of Communication Sciences.

32 Not only the innovators are interested in it, but also the rest of the market, by which the package has a bigger chance of being adopted by a larger share of the market.

33 There is a good chance this copy behaviour will take place, because it is a package in which they are interested, they have to copy.

34 This strategy of only using specific targeting does not only have to be used to promote A4 and A5 towards innovators and early adopters. It can also be used to promote other applications with a specific segment-related interest: for example to promote home shopping to those young couples within the early adopters, or to promote proton to students. 